\title{
Bronchioloalveolar carcinoma arising in longstanding
} lung cysts

\author{
MG PRICHARD, PJE BROWN, GF STERRETT \\ From the Sir Charles Gairdner Hospital, Queen Elizabeth II Medical Centre, Nedlands, Western Australia
}

ABSTRACT Two adults, both non-smokers, with large peripheral lung cysts, which were of long standing (12 and nine years), were found to have well differentiated mucus secreting adenocarcinomas with a bronchioloalveolar growth pattern associated with the cysts. Lobectomy is likely to have been curative in one of the cases and earlier surgery might have been so in the other. The fact that many of the reported carcinomas associated with lung cysts have developed at an early age, as well as some histological features, suggests that the association is not coincidental; and early surgery for lung cysts is therefore recommended.

The common complications of longstanding, presumed congenital, lung cysts are infection, haemorrhage, and rupture causing pneumothorax. In a small number of cases malignancy may also supervene; associated neoplasms of various types, including adenocarcinoma, squamous cell carcinoma, and undifferentiated carcinoma in adults (table 1) and blastoma in children ${ }^{12}$ have been reported. We have recently seen two examples of well differentiated mucinous adenocarcinoma of bronchioloalveolar growth pattern arising in large peripheral cysts in adults; this particular association has not previously been reported.

\section{Case reports}

\section{CASE 1}

A 30 year old woman (a non-smoker) presented with a six week history of malaise and intermittent productive cough unresponsive to antibiotics. Multiple cysts in the left lower lobe had been seen on a chest radiograph 12 years previously when she was investigated for possible pneumonia. Although the patient appeared well and was afebrile her chest radiograph showed fluid levels in several cysts (fig 1) and she was treated with systemic antibiotics. She remained afebrile, sputum culture was negative, and after five days the radiographic appearances were

\footnotetext{
Address for reprint requests: Dr GF Sterrett, Sir Charles Gairdner Hospital, Queen Elizabeth II Medical Centre, Nedlands, Western Australia, 6009.
}

Accepted 16 January 1984 unchanged. Fibreoptic bronchoscopy showed normal bronchial anatomy; segmental divisions of the left lower lobe were visualised and were patent. Bilateral bronchography failed to reveal bronchiectasis; no bronchial communication with any of the cysts could be demonstrated. An aortogram showed normal thoracic and abdominal vasculature with no ectopic vessels, excluding a sequestered bronchial segment. A left lower lobectomy was performed.

\section{Pathological findings}

Most of the lobe was replaced by multilocular, mainly airfilled cysts measuring from 1 to $4 \mathrm{~cm}$ in diameter (fig 2). Lung parenchyma at the apex and the base of the lobe was normal, but there were several discrete areas of solid, mucoid tissue extending from the edge of the cysts into parenchyma (fig 2 , arrows). Bronchi away from the cyst were normal and did not communicate with the cystic spaces.

Microscopically the cysts were lined by tall columnar, mucus secreting epithelium and some ciliated cells. Their walls consisted of vascular connective tissue containing elastic tissue and a small amount of smooth muscle. Neither cartilage nor seromucinous glands were present. The solid mucoid areas were foci of well differentiated bronchioloalveolar carcinoma (fig 3, open arrow), which merged with hyperplastic mucinous epithelium at the edges of the cysts (fig 3, large arrow). There was no evidence of carcinoma in lymph nodes.

\section{CASE 2}

A 41 year old Eurasian woman (a non-smoker) was found to have a solitary thin walled cyst, situated in 
Carcinoma complicating longstanding lung cysts in adults

\begin{tabular}{|c|c|c|c|c|}
\hline Authors & Age & Sex & Description & Type of carcinoma \\
\hline $\begin{array}{l}\text { Moersch }^{5} \\
\text { Moersch' } \\
\text { Konwaler and Hyde } \\
\text { Bass and Singer }{ }^{10} \\
\text { Bauer' } \\
\text { Huntington et al }{ }^{12} \\
\text { Larkin and Phillips } \\
\text { Peabody' } \\
\text { Svennevig et al } \text { al }^{15} \\
\text { West and van } \\
\text { Schoonhoven } \\
\text { Present authors }\end{array}$ & $\begin{array}{l}22 \\
36 \\
42 \\
59 \\
30 \\
43 \\
53 \\
54 \\
66 \\
34 \\
32 \\
58\end{array}$ & $\begin{array}{l}\mathbf{F} \\
\mathbf{M} \\
\mathbf{M} \\
\mathbf{M} \\
\mathbf{M} \\
\mathbf{F} \\
\mathbf{M} \\
\mathbf{M} \\
\mathbf{F}\end{array}$ & $\begin{array}{l}\text { Bronchogenic } \\
\text { Unspecified type, solitary, calcified } \\
\text { Bronchogenic } \\
\text { Unspecified type, multiple } \\
\text { Unspecified type, solitary thin walled } \\
\text { Unspecified type } \\
\text { Unspecified type, solitary } \\
\text { Unspecified type, solitary } \\
\text { Unspecified type, solitary thin walled } \\
\text { Unspecified type } \\
\text { Multiple peripheral, "congenital" } \\
\text { Bronchogenic }\end{array}$ & $\begin{array}{l}\text { Adenocarcinoma } \\
\text { Squamous cell } \\
\text { Squamous cell } \\
\text { Adenosquamous } \\
\text { Combined squamous and oat cell } \\
\text { Squamous cell } \\
\text { Squamous cell } \\
\text { Undifferentiated } \\
\text { Adenocarcinoma } \\
\text { Undifferentiated large cell } \\
\text { Adenocarcinoma (multifocal mucinous } \\
\text { bronchioloalveolar) } \\
\text { Adenocarcinoma (mucinous } \\
\text { bronchioloalveolar) }\end{array}$ \\
\hline
\end{tabular}

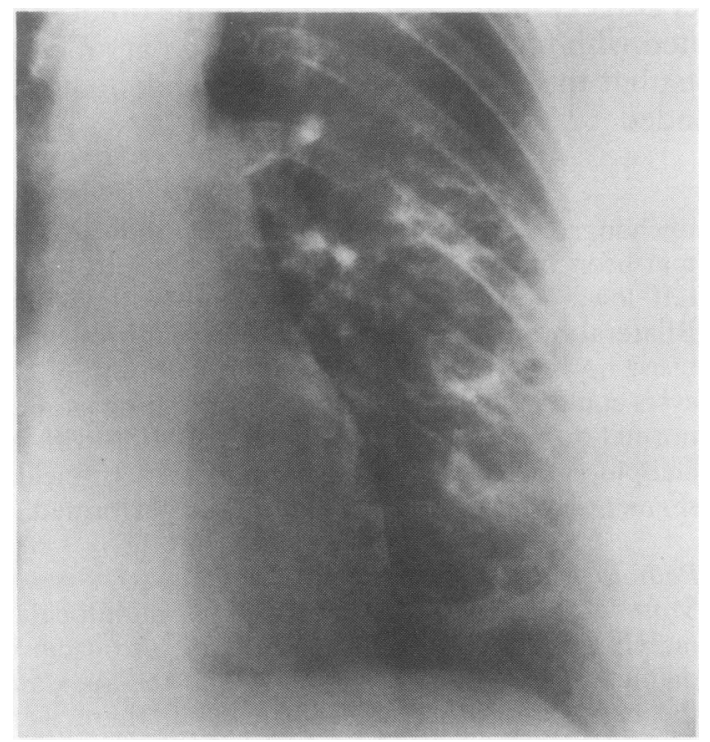

Fig 1 Posteroanterior chest radiograph (detail, left lung), showing multiple cysts with fuid levels in the left lower lobe.

the apex of the left lower lobe, on a routine chest radiograph. One year later she developed a fluid level in the cyst and at the same time complained of a productive cough. Both of these features cleared after antibiotic treatment. The patient remained free of respiratory symptoms and the radiographic appearances were unchanged for nine years, at the end of which she presented with a four week history of productive cough and dull left sided chest pain. The chest radiograph showed fluid in the cyst and an adjacent ill defined mass (fig 4, arrow). As the appearances remained unchanged after one month's treatment with antibiotics and postural drainage, a left bronchogram was performed. This showed normal appearances except for some displacement of the bronchopulmonary segments next to the cyst. of No communication was demonstrated between the $O$ cyst and the bronchial tree. A left pneumonectomy was performed during a diagnostic thoractomy.

The patient died two and a half years after presentation, from metastatic tumour; postmortem examination was not performed.

\section{Pathological findings}

At thoracotomy there was a solitary subpleural, cystic structure, $6 \mathrm{~cm}$ in maximum diameter, within the left lower lobe. The cyst wall was fibrous and about $0.5 \mathrm{~cm}$ in thickness except for one focus of nodular tumour tissue $2 \times 2 \times 1 \mathrm{~cm}$. An ill defined parenchymal mass $5.5 \times 3 \times 2.5 \mathrm{~cm}$ with a mucoid, yellow grey cut surface lay beside the cyst wall and extended across the interlobular fissure, affecting the upper lobe parenchyma.

The cyst wall was lined by ciliated columnar epithelium and consisted of fibroelastic tissue, blood vessels, and scattered glands lined by tall, mucus secreting columnar cells (fig 5, small arrow). There were also foci of adenocarcinoma, presenting mainly as well formed glands (fig 5, large arrow). Within the lung parenchyma the carcinoma was well differenti- $\bigcirc$ ated and consisted of tall, mucus secreting cells lining up along alveolar septa (fig 6). Metastatic carcinoma was present in several hilar lymph nodes.

\section{Discussion}

Although a congenital origin was not proved, both lungs cysts were unquestionably long standing and

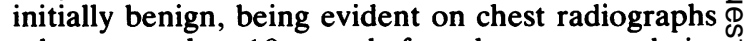
taken more than 10 years before the present admis- $\cdot$ sions. Bronchography and the clinical and pathological features excluded bronchiectatic cysts. Neither $\frac{0}{\mathbb{D}}$ case was associated with lobular sequestration. In $\stackrel{?}{\stackrel{9}{P}}$ case 1 the gross and histological appearances con- $\mathbb{\mathbb { Q }}$ form to descriptions of peripheral congenital lung 


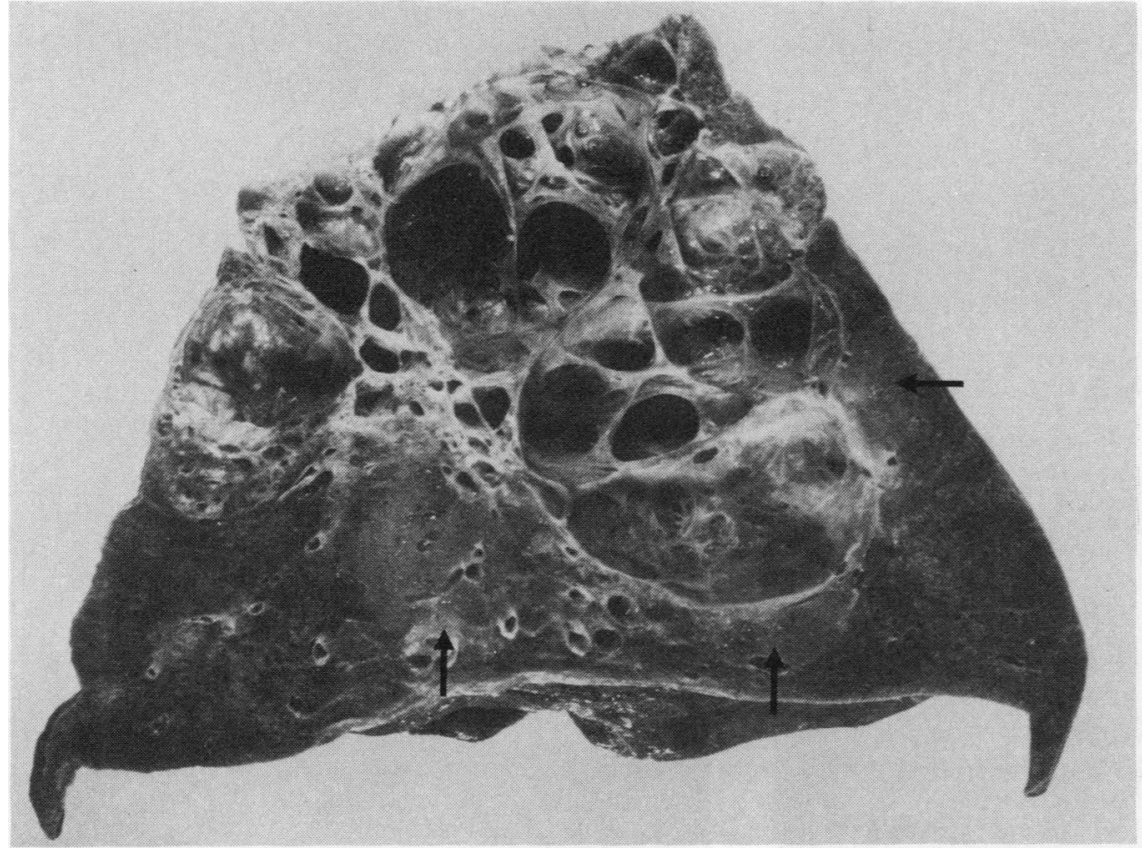

Fig 2 Thin walled cysts within the left lower lobe. Note the multiple foci of mucoid tumour tissue (arrows) next to the cyst wall.

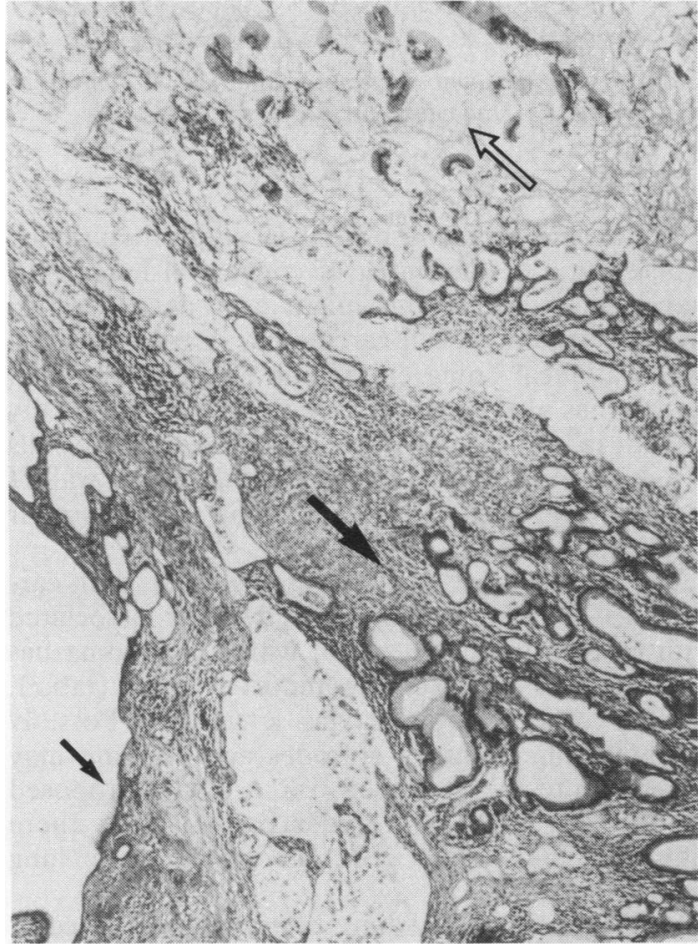

Fig 3 Cyst wall (small arrow) together with hyperplastic mucinous epithelium (large arrow) adjacent to the well differentiated mucinous bronchioloalveolar carcinoma (open arrow). (Haematoxylin and eosin, $\times 68$.)

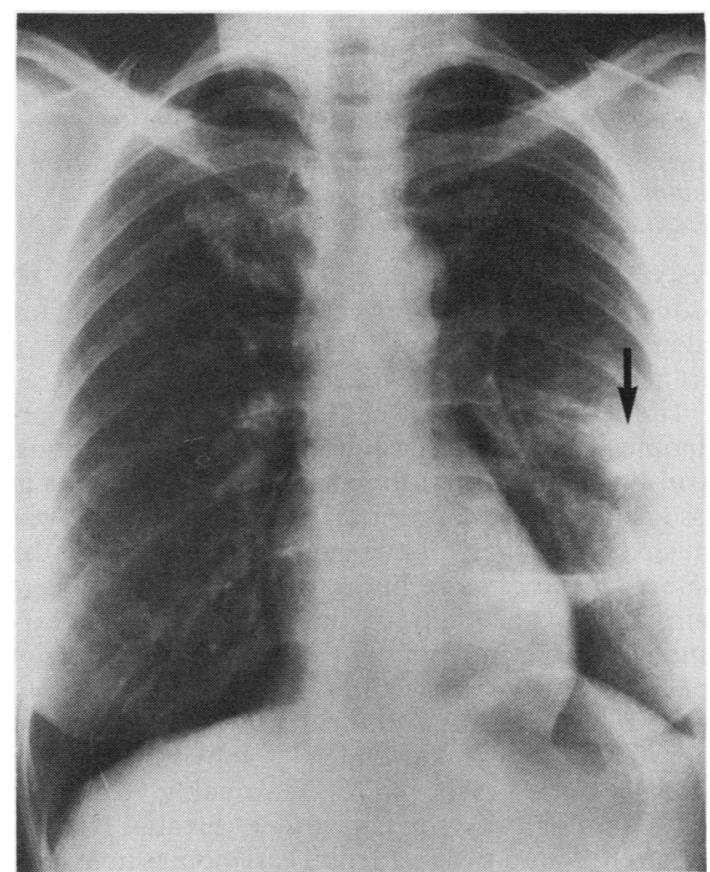

Fig 4 Posteroanterior chest radiograph, showing solitary cyst with fuid level in the apical segment of the left lower lobe and adjacent tumour mass (arrow). 


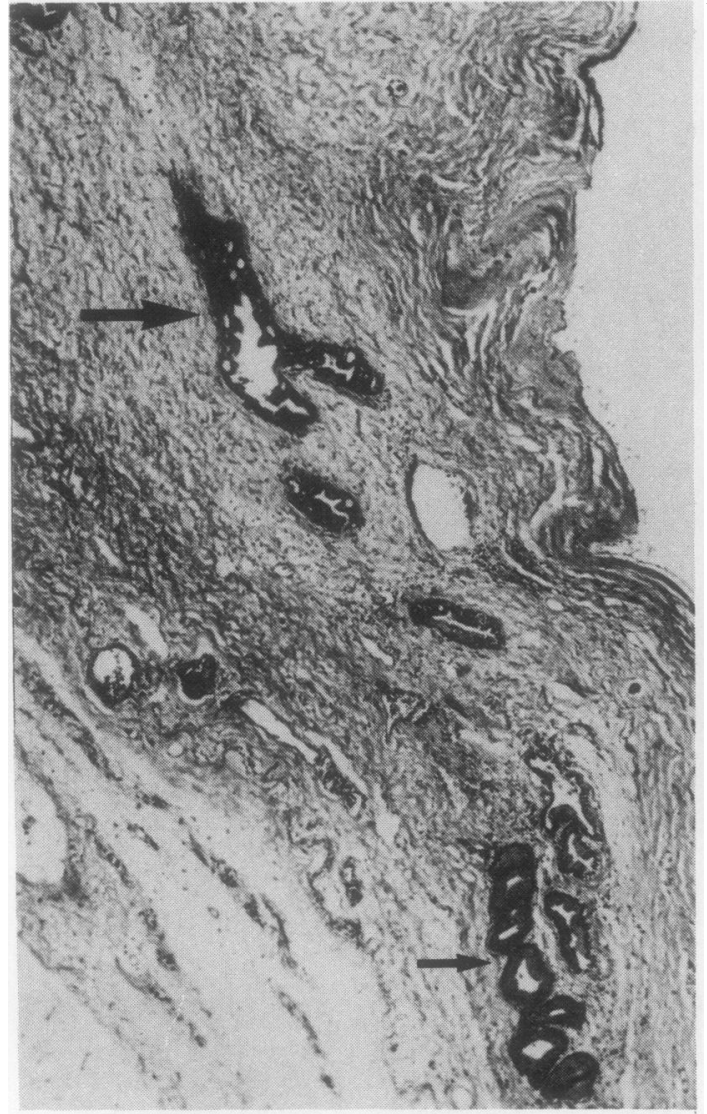

Fig 5 Wall of lung cyst showing both benign (small arrow) and malignant (large arrow) mucinous glands

(Haematoxylin and eosin, $\times 55$.)

cysts; ${ }^{3}$ in case 2 the cyst was thought to be bronchogenic. In both cases the accompanying adenocarcinomas were mucus secreting with a bronchioloalveolar growth pattern.

The relationship between lung cysts and lung carcinomas has been discussed in several publications. Korol ${ }^{4}$ concluded that the incidence of carcinoma in association with "congenital cystic emphysema" was much higher than in the general population; the nature of the cysts in his cases, however, is uncertain. Indeed, in many of the case reports of carcinoma arising in cysts the exact type of cyst is not specified. Further discussion is therefore limited to those reports in which the cysts were known to be longstanding, and in which emphysematous or bronchiectatic cysts were reasonably excluded histopathologically or by other means (table). Moersch ${ }^{5}$ found two incidental carcinomas in association with 44 histologically examined cysts, 36 of which were considered to be bronchogenic.

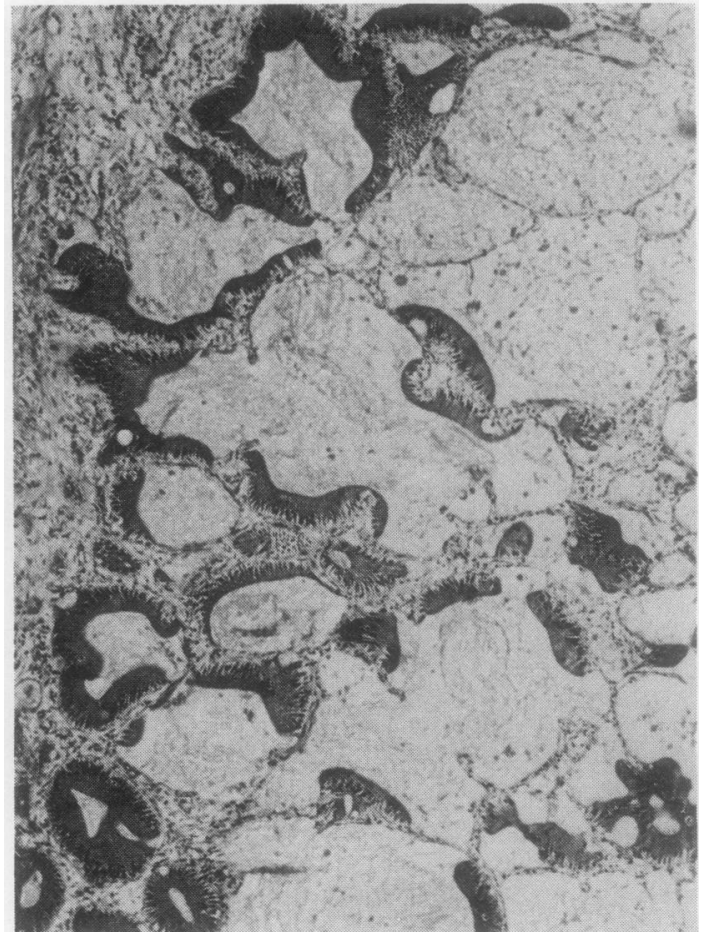

Fig 6 Mucinous adenocarcinoma with bronchioloalveolar growth pattern. (Haematoxylin and eosin, $\times 60$ ).

Womack and Graham ${ }^{6}$ described atypical epithelia proliferation of the lining of congenital lung cysts, and speculated that this might precede or lead to invasive squamous cell carcinoma. A transition between atypical lining epithelium and adjacent carcinoma has also been described ${ }^{7}$; this was strikingly evident in our case 1 . In case 2 the neoplastic cells closely resembled benign mucous cells in the wall of the cyst, suggesting a possible origin of the tumour from these cells.

To us the most convincing evidence that carcinomas are not simply coincidentally associated N with cysts is the early age at which carcinoma has developed in many of the reported cases (table). $N$ Neither of our patients was a smoker. Possibly $\underset{\omega}{N}$ repeated inflammatory episodes and scarring may contribute to the increased risk, a theory proposed 0 for the scar cancers of older patients; but there $\overparen{\varnothing}$ may also be innate risk, associated with lung? maldevelopment.

Surgical removal of lung cysts has been recommended because of the high incidence of complications in the form of infection, haemorrhage, and $\stackrel{\mathbb{Q}}{\unrhd}$ rupture producing pneumothorax. One other argu- 
ment in favour of early surgery is that definitive diagnosis of the type of cyst may not be possible before thoracotomy; several authors have drawn attention to the presentation of bronchogenic carcinoma as thin walled, apparently innocuous cysts. ${ }^{89}$ We believe that the cases presented here offer further evidence of the need for early surgery for lung cysts because of the risk of associated carcinoma. In case 1 lobectomy is likely to have been curative; in case 2 surgery at the time of the earlier presentation might also have been curative.

\section{Addendum}

Since this article was submitted, Avitabile et al (Am J Surg Pathol 1984;8:193-202) have described several cases of cystic lung disease in adults, which they attribute to persistence of congenital cystic adenomatoid malformation. Our case 1 closely resembles their cases. The authors caution that the abundant mucinous epithelial components present within the lesions could lead to an erroneous diagnosis of bronchioloalveolar carcinoma. We have reviewed our material in the light of these observations. In our case 1 there is hyperplastic epithelium among the cysts; the diagnosis of carcinoma is, however, justified by the extensive growth of mucinous epithelium along alveolar walls at some distance from the cysts.

\section{References}

' Weinberg AG, Currarino G, Moore GC, Votteler TP. Mesenchymal neoplasia and congenital pulmonary cysts. Pediatr Radiol 1980;9:179-82.

2 Weinblatt ME, Siegel SE, Isaacs H. Pulmonary blastoma associated with cystic lung disease. Cancer 1982;49:669-71.

${ }^{3}$ Spencer H. Pathology of the lung. Vol 1. Oxford: Pergamon Press, 1977.

${ }^{4}$ Korol E. The correlation of carcinoma and congenital cystic emphysema of the lungs. Report of ten cases. Dis Chest 1953;23:403-11.

' Moersch HJ. Pulmonary cysts. J Thorac Surg 1947; 16: 179-94.

' Womack NA, Graham EA. Epithelial metaplasia in congenital cystic disease of the lung. Am J Pathol 1941; 17:645-53.

${ }^{7}$ Konwaler BE, Hyde L. Carcinoma arising in a congenital lung cyst. J Lancet $1965 ; 85: 438-40$.

" Anderson JH, Pierce JW. Carcinoma of the bronchus presenting as thin-walled cysts. Thorax 1954;9:100-5.

${ }^{4}$ Peabody JW, Rupnik EJ, Hanner JM. Bronchial carcinoma masquerading as a thin-walled cyst. Am J Roentgenol 1957;77:1051-4.

"' Bass HE, Singer E. Coexisting lobar adenocarcinoma and cystic disease of the lung. Ann Intern Med 1951;34:498-507.

"Bauer S. Carcinoma arising in a congenital lung cyst. Dis Chest 1961;40:552-5.

12 Huntington HW, Poppe JK, Goodman MJ. Carcinoma arising in a congenital cyst of the lung. Dis Chest 1963;44:329-32.

${ }^{13}$ Larkin JC, Phillips S. Carcinoma complicating cyst of lung. Dis Chest 1955;27:453-7.

${ }^{14}$ Peabody JW, Katz S, Davis EW. Bronchial carcinoma arising in a lung cyst. Am $J$ Roentgenol 1957;77: 1048-50.

is Svennevig J, Bugge-Asperheim B, Boye NP. Carcinoma arising in a lung cyst. Scand J Thorac Cardiovasc Surg 1979; 13:153-5.

${ }^{16}$ West JP, Van Schoonhoven PV. Carcinoma of the lung developing in a congenital cyst. Surgery 1957;42: 1071-6. 